\title{
The Influence of Mergers and Acquisitions on Competitiveness of Economies of Countries of the World
}

\author{
${\text { Viktoriia } \text { Khaustova }^{1} \text {, Tetyana Kolodyazhna }}^{2}$ and Hennadii Kramarev ${ }^{3}$ \\ ${ }^{1}$ Research Centre for Industrial Problems of Development of NAS of Ukraine, Sector of Industrial Policy \\ and Innovative Development, 1-a Inzhenernyi Ln., Kharkiv, 61166, Ukraine \\ ${ }^{2}$ Kharkiv National University of Construction Engineering and Architecture, Department of Finance, 40 \\ Sumska Str., Kharkiv, 61002, Ukraine \\ ${ }^{3}$ Research Centre for Industrial Problems of Development of NAS of Ukraine, Applicant, 1-a Inzhenernyi \\ Ln., Kharkiv, 61166, Ukraine
}

\begin{abstract}
Today, the most important factor which determines the development of the world economy is economic globalization. The article presents a scheme of the interdependence of the processes that determine competitiveness of the country in the context of globalization: CER.1 - the cause-effect relation reflecting the influence of M\&A with the participation of national companies on concentration of a national economy; CER.2 - reflecting the impact of concentration of the national economy on its competitiveness; CER.3 reflecting the impact of intensity of M\&A with the participation of national companies on their capitalization; CER.4 - reflecting the impact of the level of national companies' capitalization on competitiveness of the country. The article puts forward and proves, based on the confirmation of the above mentioned cause-effect relations, the following hypotheses: 1. - merges and acquisitions with the participation of national companies influence concentration of a national economy which in turn determines the level of its competitiveness; 2. integration with the participation of national companies through implementation of M\&A increases their market capitalization, thereby affecting the level of competitiveness of the country. For simulating, the correlation and regression modeling is used. The statistical base of the study comprises a sample of 42 countries of the world.
\end{abstract}

\section{Introduction}

In a modern economy, competitiveness of the country determines the level of its socio-economic development. At the same time, today the most important factor determining the development of the world economy is economic globalization, the spread of which is the result of a whole range of processes taking place in society. Globalization has created new organizational forms of interaction among countries and individual companies, which allow overcoming obstacles created by state borders, and changed the conditions and the very principles of competition [1].

The basis of globalization is international economic integration, which is carried out both at the level of countries and at the level of companies. The activity of national companies in the

\footnotetext{
* Corresponding author: v.khaust@gmail.com
} 
processes of mergers and acquisitions determines the degree of concentration of the national economy (economic concentration), affects market capitalization of companies and thereby determines competitiveness of the country.

The analysis of the scientific literature has shown that the influence of integration processes implemented through mergers and acquisitions of companies on competitiveness of an economy is insufficiently studied. The above indicates the relevance of further research on the outlined issue.

\section{Theoretical basis and methodology}

Within the framework of this research, it is proposed to understand competitiveness of the country as the ability of its scientific and technical resources and implemented economic policy to ensure the production of goods and services which are in demand in the market and create conditions for sustainable economic growth of the country and improvement of living standards of its population.

As mentioned earlier, the modern development of the world economy and competitive processes in it is determined by globalization of the world economy. The pace of globalization has intensified since the beginning of the 21 st century and its processes are accompanied by amalgamation of economic entities, internationalization of national economies and, accordingly, growth in economic concentration [2]. Under these conditions, activities of transnational corporations (TNCs) have gained particular importance, and their influence on the economy of an individual country and development trends in the world economy increased significantly [3]. Thus, in the world, there observed a steady trend towards the spread of concentration processes both at the level of economies and that of individual industries and economic entities, the major concentration taking place within TNCs.

The analysis of the modern scientific literature has shown that the concept "concentration" is used by scientists and practitioners in different meanings and in relation to various levels of the economy and objects under consideration (economy, industry, market, etc.) [4]. In our opinion, concentration of capital should be investigated from two standpoints: 1 - as a result of the conversion of profits into capital by capitalizing surplus value; 2 - as strengthening capital through consolidating the capital of various owners [5]. Based a number of the most common definitions of the concept "concentration of an economy", in this study, it is proposed that the essence of the concept "concentration of an economy" be interpreted as degree of concentration of production volumes or provision of services by the largest national companies in relation to the national GDP.

In world economic practice, there are three main options for the development of companies which imply: 1 - independent internal development of tangible and intangible assets; 2 - gaining competitive advantages on a contractual basis, i.e., outsourcing; 3 - mergers and acquisitions (M\&A). Despite the fact that many companies are successfully building their internal growth strategy, in recent decades, M\&A are increasingly becoming the main competitive strategy, being the fastest way to acquire assets and expand into new types of sales markets, etc. According to experts, almost $80 \%$ of all international investments are directed not to establishing new companies abroad but to acquiring assets of existing ones. Due to this, in the second half of the 20th century, the processes of concentration of production and centralization of capital manifested themselves in an avalanche-like increase in the number and value of M\&A transactions in economies of different countries of the world. The intensity and focus of M\&A processes are reflected in assessments of the level of concentration of the economy at all levels of its hierarchy. The state of development of the national economy and its competitiveness depend on the state of economic concentration. In this context, another manifestation of integration processes is reflected, in particular, that integration results in an increase in the market value (capitalization) of an integrated entity, making it more "strong" and competitive [6]. 
Thus, based on the above analysis, the following research hypotheses are put forward:

- the hypothesis on the impact of M\&A processes with the participation of national companies (as one of the most common forms of integration) on the economic concentration in a country and its level of competitiveness;

- the hypothesis on the impact of integration processes with the participation of national companies through implementation of $M \& A$ on the level of their market capitalization and the level of competitiveness of a country.

Accordingly, it is proposed to analyze the impact of integration processes through M\&A on competitiveness of economies of countries of the world by proving or refuting the hypotheses put forward with the help of identifying a number of cause-effect relations (CERs) (Fig. 2).

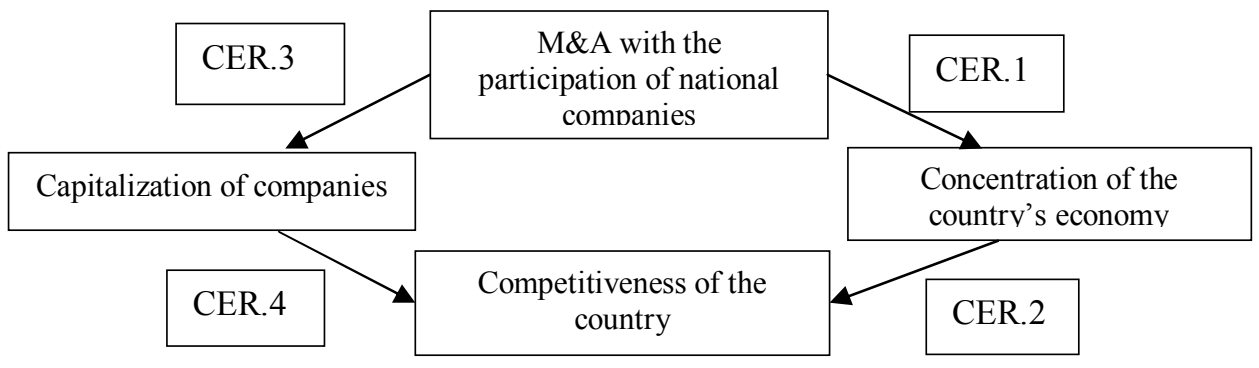

Fig. 2 Scheme of the interdependence of the processes that determine competitiveness of the country in the context of globalization, where: CER.1 is the cause-effect relation reflecting the influence of M\&A with the participation of national companies on concentration of a national economy; CER. 2 - reflecting the impact of concentration of a national economy on its competitiveness; CER.3 - reflecting the impact of intensity of M\&A with the participation of national companies on their capitalization; CER.4 - reflecting the impact of the level of national companies' capitalization on competitiveness of the country.

Source: developed by the authors

Considering the objectives of this study - to prove or refute the hypotheses put forward by assessing the strength and direction of the relationship between certain factors and to establish the analytical expression of the dependence between them - the correlation and regression modeling is used. To solve the problem, a pair correlation, which demonstrates the strength and direction of relationship between the influencing and resultant factors, is applied. For a qualitative assessment of the relationship, the Cheddok scale is used. The statistical base of the study is compiled from a sample of 42 countries of the world. The calculations are carried out using the Statistica software package.

\section{Results}

According to the research objectives and scheme of the relationship of the processes determining competitiveness of the country shown in Fig. 2, there investigated:

1. The impact of integration processes of M\&A with the participation of national companies on the level of their market capitalization. To determine the relationship between M\&A of companies and their capitalization, the following indicators are used: the relative index of M\&A volume $\left(\mathrm{I}_{\mathrm{MA}}\right)$ and the relative index of market capitalization $\left(\mathrm{I}_{\text {cap }}\right)$. The relative index of $M \& A$ volume $\left(\mathrm{I}_{\mathrm{MA}}\right)$ is calculated as the ratio of volume of transactions on M\&A of companies (according to the World Investment Report published by UNCTAD [7]) to GDP of the countries in which they were created (according to the World Bank [9]). The relative index of market capitalization $\left(\mathrm{I}_{\text {cap }}\right)$ is calculated as the ratio of market capitalization of the largest companies (according to Forbes 2000 [8]) to GDP of the countries in which they were created (according to the World Bank [9]). 
As a result of the calculations, the following models characterizing the impact of M\&A processes on capitalization of companies involved are obtained: linear; exponential; $2^{\text {nd }}-, 3^{\mathrm{d}}-$; $4^{\text {th }}-; 5^{\text {th }}$ - and $6^{\text {th }}$ degree polynomial. The $6^{\text {th }}$ degree polynomial dependency, presented in Fig. 3 , has the highest coefficient of determination between the indexes $\left(\mathrm{R}^{2}=0.7091\right)$. Thus, the analysis of the relationship between M\&A volume and market capitalization of companies involved has made it possible to substantiate the following statement: the countries in which M\&A processes are more intensive have a higher level of capitalization of companies involved.

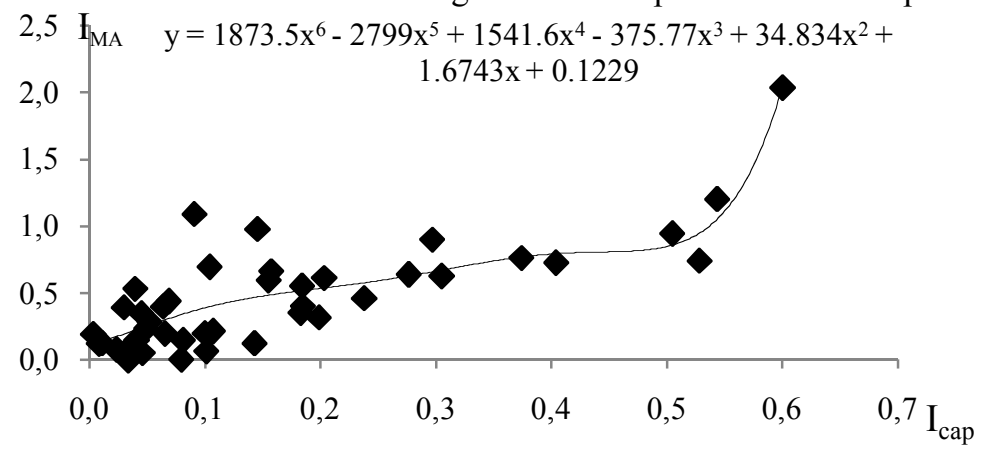

Fig. 3. The $6^{\text {th }}$ degree polynomial correlation and regression model of the impact of M\&A processes $\left(\mathrm{I}_{\mathrm{MA}}\right)$ on capitalization of companies involved $\left(\mathrm{I}_{\text {cap }}\right)$

Source: developed based on the authors' calculations

2.The impact of capitalization of national companies on competitiveness of a country. To determine the relationship between market capitalization of national companies and competitiveness of the country in which they were created, the following indicators are used: the relative index of market capitalization $\left(\mathrm{I}_{\text {cap }}\right)$ and the relative index of competitiveness of the national economy $\left(\mathrm{I}_{\text {com }}\right)$. The relative index of market capitalization $\left(\mathrm{I}_{\text {cap }}\right)$ is calculated as the ratio of market capitalization of the largest companies (according to Forbes 2000 [8]) to GDP of the countries in which they were created (according to the World Bank [9]). The relative index of competitiveness of the national economy $\left(\mathrm{I}_{\text {com }}\right)$ is calculated as the Global Competitiveness Index (GCI) of the WEF [10].

As a result of the calculations, the models characterizing the impact of capitalization of national companies on competitiveness of economies of the countries are obtained. The $6^{\text {th }}$ degree polynomial dependency (Fig. 4) has the highest coefficient of determination between the indexes $\left(\mathrm{R}^{2}=0.6729\right)$. Thus, the conducted study has allowed to confirm the existence of the cause-effect relation CER.4 and substantiate the statement: the countries of the world whose companies have higher capitalization have a higher competitiveness of the economy.

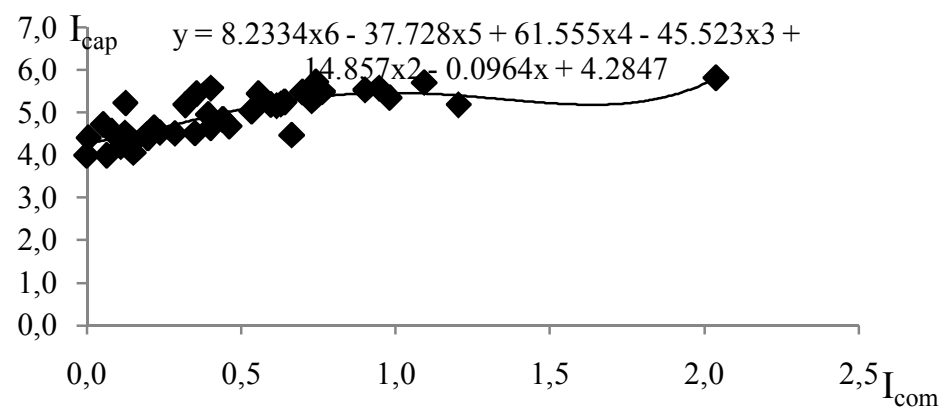

Fig. 4. The $6^{\text {th }}$ degree polynomial correlation and regression model of the impact of capitalization of companies $\left(\mathrm{I}_{\text {cap }}\right)$ on competitiveness of the national economy $\left(\mathrm{I}_{\text {com }}\right)$

Source: developed based on the authors' calculations 
3. The impact of M\&A processes with the participation of national companies on economic concentration in a country. To determine the relationship between $\mathrm{M} \& \mathrm{~A}$ with the participation of national companies and economic concentration in a country, the following indicators are used: the relative index of M\&A volume $\left(\mathrm{I}_{\mathrm{MA}}\right)$ and the relative index of concentration of an economy $\left(\mathrm{I}_{\mathrm{co}}\right)$. As in previous models, the relative index of M\&A volume $\left(\mathrm{I}_{\mathrm{MA}}\right)$ is calculated as the ratio of volume of M\&A transactions (according to the World Investment Report published by UNCTAD [7]) to GDP of the countries in which they were created (according to the World Bank [9]). The relative index of concentration of an economy $\left(\mathrm{I}_{\mathrm{co}}\right)$ is calculated as the ratio of sales of the largest companies (according to Forbes 2000 [8]) to GDP of the countries in which they were created (according to the World Bank [9]).

As a result of the calculations, there obtained models which characterize the impact of M\&A processes on concentration of the national economy. The $6^{\text {th }}$ degree polynomial dependency (Fig. 5) has the highest coefficient of determination between the indexes $\left(\mathrm{R}^{2}=0.6406\right)$. Thus, the study has allowed to confirm the cause-effect relation CER.1 and substantiate the statement: the countries of the world whose companies are more active in M\&A processes have a higher degree of economic concentration.

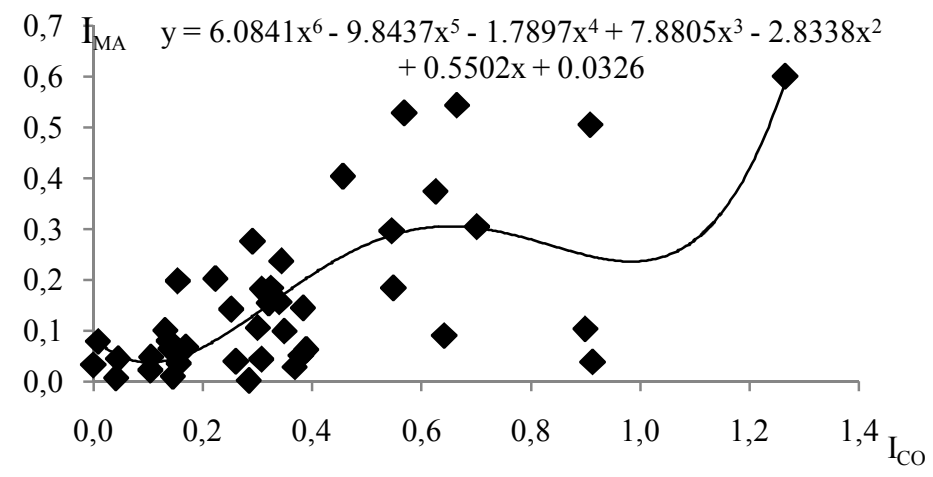

Fig. 5. The $6^{\text {th }}$ degree polynomial correlation and regression model of the impact of M\&A processes $\left(\mathrm{I}_{\mathrm{MA}}\right)$ on concentration of economies of the countries of the world $\left(\mathrm{I}_{\mathrm{co}}\right)$

Source: developed based on the authors' calculations

3. The impact of concentration of the national economy on competitiveness. To determine the relationship between the concentration of the national economy and its competitiveness, the following indexes are used: the relative index of concentration of economy $\left(\mathrm{I}_{\mathrm{co}}\right)$ and the relative index of competitiveness of the national economy $\left(\mathrm{I}_{\mathrm{com}}\right)$. As in previous models, the relative index of concentration of an economy $\left(\mathrm{I}_{\mathrm{co}}\right)$ is calculated as the ratio of sales of the largest companies (according to Forbes 2000 [8]) to GDP of the countries in which they were created (according to the World Bank [9]). The relative index of competitiveness of the national economy $\left(\mathrm{I}_{\mathrm{com}}\right)$ is calculated as the Global Competitiveness Index $(\mathrm{GCI})$ of the WEF [10].

As a result of the calculations, the models characterizing the impact of concentration of the national economy on its competitiveness are obtained. The $6^{\text {th }}$ degree polynomial dependency (Fig. 6) has the highest coefficient of determination between the indexes $\left(\mathrm{R}^{2}=0.7137\right)$. Thus, this has allowed to confirm the cause-effect relation CER.2 and substantiate the statement: countries of the world with a higher degree of economic concentration are more competitive.

\section{Conclusions}

Consequently, the confirmation of the above cause-effect relations (CER.1 - CER.4) has made it possible to prove the hypotheses put forward in this study (Fig. 1), namely: 1-M\&A 


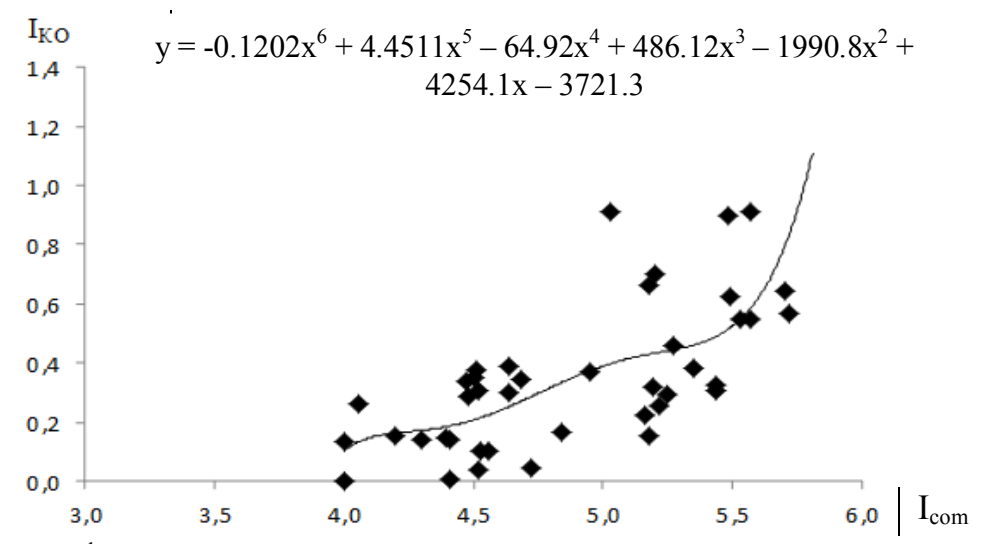

Fig. 6. The $6^{\text {th }}$ degree polynomial correlation and regression model of the impact of concentration of the national economy $\left(\mathrm{I}_{\mathrm{co}}\right)$ on competitiveness of the country $\left(\mathrm{I}_{\text {com }}\right)$

Source: developed based on the authors' calculations

with the participation of national companies influence concentration of the national economy which in turn determines the level of its competitiveness; 2 - Integration with the participation of national companies through implementation of $\mathrm{M} \& \mathrm{~A}$ increases their market capitalization, thereby affecting the level of competitiveness of the country.

The carried out research suggests that national governments should pay attention to conditions for the implementation of integration processes in the countries, their stimulation and control (including antimonopoly control). Measures to support and stimulate the development of integration processes should be aimed at the formation of effective national integrated business structures with a sufficient amount of investment resources. The presence of such structures in key sectors of the national economy is the key to security of the national economy, the competitiveness of the country and the basis for the growth of the level and quality of life of its people.

\section{References}

1. Gelvanovsky, M. Competitiveness of the national economy: problems of statistical support. Economic issues, 7, 3-15 (2004)

2. Walter, J. Competitiveness: a common approach. Russian-European Center for Economic Policy, 52 p. (2005)

3. Limonova, E., Arkhipova, K. Transnational corporations: the main stages of development and regulation of their activities in the conditions of globalization. European vector of economic development, 1(16), 93-101 (2014)

4. Kyzym, M., Gorbatov, V. Concentration of economy and competitiveness of countries of the world. PH "INZHEK", 216 p. (2005)

5. Khaustova, V., Kolodyazhna, T. Influence of Mergers and Acquisitions on the Competitiveness of the Economy in the Conditions of Globalization, Publisher Liburkina L., 416 p. (2019)

6. Zagorsky, V., Khaustova, V. Theoretical Aspects of Capitalization of Entities. Innovations: Problems of Science and Practice. PH "INZHEK", 176-192 (2009)

7. UNCTAD. http://stats.unctad.org

8. Forbes Magazine. https://www.forbes.com

9. World Bank. https://data.worldbank.org/indicator/

10. World Economic Forum 2017. The Global Competitiveness Report 2016-2017. https://www.weforum.org/ reports/the-global-competitiveness-report-2017-2018 